\title{
Integrated polymer waveguides for absorbance detection in chemical analysis systems
}

\author{
Mogensen, Klaus Bo; El-Ali, Jamil; Wolff, Anders; Kutter, Jörg Peter
}

Published in:

Proceedings of the 12th International Conference on Solid-State Sensors, Actuators and Microsystems (Transducers)

Publication date:

2003

Document Version

Publisher's PDF, also known as Version of record

Link back to DTU Orbit

Citation (APA):

Mogensen, K. B., El-Ali, J., Wolff, A., \& Kutter, J. P. (2003). Integrated polymer waveguides for absorbance detection in chemical analysis systems. In Proceedings of the 12th International Conference on Solid-State Sensors, Actuators and Microsystems (Transducers) (Vol. 1, pp. 694-967). IEEE.

\section{General rights}

Copyright and moral rights for the publications made accessible in the public portal are retained by the authors and/or other copyright owners and it is a condition of accessing publications that users recognise and abide by the legal requirements associated with these rights.

- Users may download and print one copy of any publication from the public portal for the purpose of private study or research.

- You may not further distribute the material or use it for any profit-making activity or commercial gain

- You may freely distribute the URL identifying the publication in the public portal 


\title{
INTEGRATED POLYMER WAVEGUIDES FOR ABSORBANCE DETECTION IN CHEMICAL ANALYSIS SYSTEMS
}

\author{
Klaus B. Mogensen, Jamil El-Ali, Anders Wolff and Jörg P. Kutter \\ Mikroelektronik Centret (MIC), Technical University of Denmark (DTU), Building 345 East, 2800 Lyngby, Denmark. \\ Tel.: +45 452557 97, Fax: +45887762, e-mail: kbm@mic.dtu.dk
}

\begin{abstract}
A chemical analysis system for absorbance detection with integrated polymer waveguides is reported for the first time. The fabrication procedure relies on structuring of a single layer of the photoresist SU-8, so both the microfluidic channel network and the optical components, which include planar waveguides and fiber-to-waveguide coupler structures, are defined in the same processing step. This results in self-alignment of all components and enables a fabrication and packaging time of only one day. The fabrication scheme has recently been presented elsewhere for fluorescence excitation of beads [1].

The emphasis of this paper is on the signal-to-noise ratio of the detection and its relation to the sensitivity. Two absorbance cells with an optical path length of 100 $\mu \mathrm{m}$ and $1000 \mu \mathrm{m}$ were characterized and compared in terms of sensitivity, limit of detection and effective path length for measurements of the dye Bromothymol Blue. The influence of three different bonding procedures on the spectrally resolved' propagation loss of the integrated waveguides between $500 \mathrm{~nm}$ and $900 \mathrm{~nm}$ was furthermore determined.
\end{abstract}

\section{INTRODUCTION}

Fluorescence detection has been the most popular optical detection method in microfluidic devices, because a good signal-to-noise ratio can be achieved in micrometer-sized channels with the use of free-space optical elements. A disadvantage of fluorescence detection is that labelling of the molecules is typically needed, which complicates the fluidic handling and alters the physical and chemical characteristics of the target molecules. Absorbance detection, on the other hand, is a more universal method, since labelling can be avoided. The disadvantage of this approach, especially in microfluidic channels, is that the limit of detection is higher due to a limited optical path length, when the depth of the channel is used for detection.

The sensitivity can be increased orders of magnitude by detection along a channel segment in the plane of the device. This has been done previously by using free-space optical elements [2,3], inserted optical fibers [4] and integrated planar waveguides $[5,6]$.

An increase in the sensitivity is, however, only desirable if it translates into an improvement of the signalto-noise ratio $(\mathrm{S} / \mathrm{N})$ of the detection; which is not necessarily the case, since the sensitivity and the baseline noise are not independent.

\section{THEORY}

The signal-to-noise ratio of the detection is typically determined by dividing the measured absorbance value with the noise of the baseline. The relation between the variance in the baseline measured in absorbance units $(\Delta \mathrm{A})$ and the variance in the light intensity $(\Delta \mathrm{I})$ can be obtained by differentiating, $A=\log \left(\mathrm{I}_{0} / \mathrm{I}\right)$, with respect to the light intensity (I). The reference intensity $\left(\mathrm{I}_{0}\right)$ is kept constant for simplicity:

$\Delta A=\frac{1}{\ln 10} \frac{\Delta I}{I}$

The governing equation for evaluation of the $\mathrm{S} / \mathrm{N}$ is thus obtained by dividing the absorbance value given by Lambert-Beer's law $(A=a b c)$ with the variance $(\Delta A)$ :

$$
\frac{A}{\Delta A}=a b c \ln 10 \frac{I}{\Delta I}
$$

$a$ is the molar absorptivity, $b$ is the optical path length (in absence of stray light) and $\mathrm{c}$ is the analyte concentration. In previous studies emphasis has mainly been on increasing the optical path length in order to improve the detection [2-6], but it is seen from eq. 2 that a reduction in the relative error of the measured light intensity $(\Delta \mathrm{I} / \mathrm{I})$ is equally important in order not to get an unpleasant surprise when evaluating the performance of the system.

\section{DESIGN AND FABRICATION}

All structures were made in the photoresist SU-8, since it is a well-established process for fabrication of thick polymer layers with a high aspect ratio [7] and because it has been widely used for fabrication of channel sidewalls in microfluidic devices $[8,9]$.

The mask design of a device is seen in Fig. 1. It consisted of microfluidic channel sidewalls, planar waveguides and fiber-to-waveguide couplers. The channel network was arranged in a cross configuration, which is typically used for capillary electrophoresis experiments. It included an $U$-shaped absorbance cell with an optical path length of $1000 \mu \mathrm{m}$ (present in the lower part of the design). Devices with channel widths of $30 \mu \mathrm{m}$ and 100 $\mu \mathrm{m}$ were fabricated. The design also contained waveguides perpendicular to the channel width in order to have a path length of $30 \mu \mathrm{m}$ and $100 \mu \mathrm{m}$, respectively. Fiber-to-waveguide coupler structures were included in

TRANSDUCERS ' 03

The 12th International Conference on Solid State Sensors, Actuators and Microsystems, Boston, June 8-12, 2003 
order to ease the optical packaging of the device. They consisted of a tapered groove were fibers can be inserted to obtain self-alignment with the waveguides. This is a similar type of approach as has been used previously for both telecommunication [10] and microfluidic devices [1, 11].

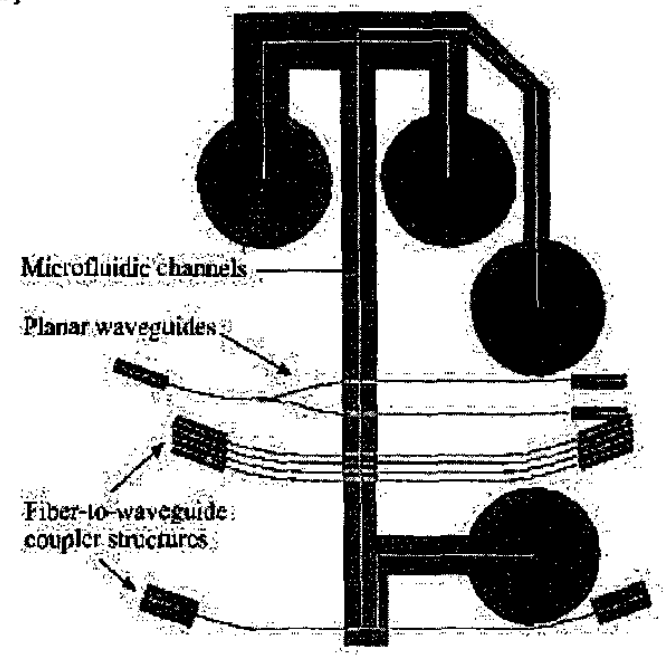

Figure 1. Mask design of a device $(3.0 \mathrm{~cm} \times 4.0 \mathrm{~cm})$ consisting of microfluidic channel sidewalls, planar waveguides and fiber-to-waveguide coupler structures. The channel network consisted of an injection cross, a separation channel and an U-shaped absorption cell.

The fabrication procedure is shown in Fig. 2. and is similar to the procedure in [1], where the waveguides were used for fluorescence excitation of beads.

a)
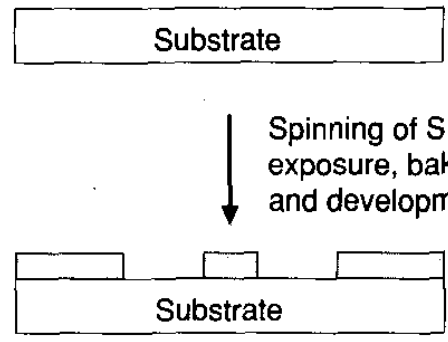

Bonding of a lid

c)

\begin{tabular}{|c|}
\hline Lid \\
\hline Substrate \\
\hline
\end{tabular}

Figure 2. Fabrication procedure for integration of SU-8 waveguides, fiber-to-waveguide couplers and microfluidic channels.
Since both the optical and fluidic elements can be defined in the same layer only a single photoresist process was needed. The substrate was a $500 \mu \mathrm{m}$ thick silicon wafer with $2.5 \mu \mathrm{m}$ thick layer of thermally grown silicon dioxide ( $\mathrm{n}=1.458$ at $635 \mathrm{~nm}$ ), which served as the waveguide cladding layer. A SU-8 layer (SU-8-2075, Microchem, U.S.A.) of $90 \pm 5 \mu \mathrm{m}$ was spun onto the substrate $(\mathrm{n}=1.59$ at $635 \mathrm{~nm})$ and patterned by standard UV photolithography. A layer thickness of $90 \mu \mathrm{m}$ was chosen, because it had to be thicker than the outer diameter of the fiber $(68 \mu \mathrm{m}$, FVP050055065, Polymicro Technologies. Phoenix, U.S.A.), which otherwise could not be inserted in the coupler grooves. A waveguide with a large core has the additional advantage that more optical power can be coupled into the waveguides. This increases the detected light intensity, which should be favorable in terms of $\mathrm{S} / \mathrm{N}$ (eq. 2).

The channel network was sealed after patterning of the SU-8 layer by bonding with either a glass or polymer lid. The lid also worked as the waveguide cladding layer. Three different bonding techniques were investigated in order to find the influence of the bonding on the waveguide properties. The three bonding techniques were: a) UV-activated adhesion bonding of a $500 \mu \mathrm{m}$ thick Borofloat lid, with the use of an intermediate layer of 5-10 $\mu \mathrm{m} \mathrm{SU}-8$, b) lamination of a $60 \mu \mathrm{m}$ thick polymer foil at $120-125^{\circ} \mathrm{C}$ and c) pressing a PMMA substrate with a 100 $\mu \mathrm{m}$ thick intermediate layer of poly(dimethylsiloxane) (PDMS) on top of the structure. It was possible to obtain a hermetically sealed lid with all three processes for channels with a width of $100 \mu \mathrm{m}$. Channels with a width of $30 \mu \mathrm{m}$ were sometimes clogged, especially in the case of the adhesion bonding, due to adhesive in the channels. This is discussed in more detail in [12].

\section{WAVEGUIDE PROPAGATION LOSS}

The spectrally resolved propagation loss of the integrated waveguides was calculated by measuring the transmission spectra of 4 waveguides with lengths between $2.52 \mathrm{~cm}$ and $4.52 \mathrm{~cm}$. The insertion loss was calculated for each waveguide by normalization with a reference spectrum of the light source. A linear fit with respect to the waveguide length was subsequently calculated in order to obtain the spectrally resolved propagation loss for the three bonding procedures as seen in Fig. 3. The best performance was achieved with the PDMS bonding yielding a propagation loss of $1.4 \mathrm{~dB} / \mathrm{cm}$ at $633 \mathrm{~nm}$. A few other groups have reported on the propagation loss of integrated polymer waveguides in microfluidic devices. McMullin [11] obtained a propagation loss of $5 \mathrm{db} / \mathrm{cm}$ at $633 \mathrm{~nm}$ for laser written waveguides based on UV-curable optical adhesive and Lee et al. [13] achieved a loss of $4 \mathrm{db} / \mathrm{cm}$ for SU-8 waveguides that were fabricated by filling pre-fabricated silicon channels with the polymer solution. 


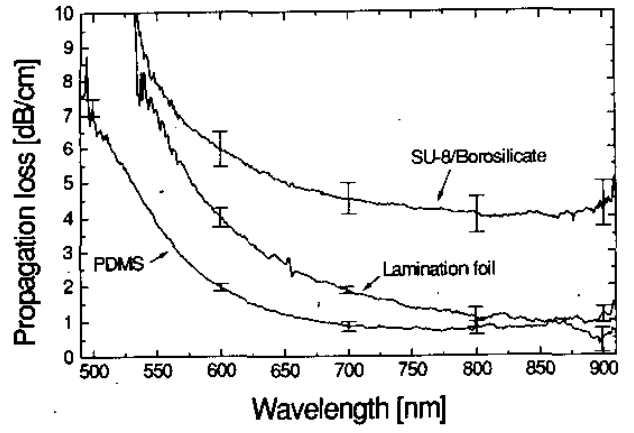

Figure 3. Spectrally resolved propagation loss between $500 \mathrm{~nm}$ and $900 \mathrm{~nm}$ of integrated waveguides fabricated with three different bonding procedures.

The propagation loss (Fig. 3) is higher at short wavelengths. This is attributed to absorption and is probably a result of the absorption tail of the photoinitiator in the resist. The waveguides with a laminated lid had a higher loss than the PDMS lid, especially at short wavelengths. This is probably caused by thermal degradation or 'yellowing' [10] during lamination, because the lamination temperature was 120 $125^{\circ} \mathrm{C}$ compared to a standard baking temperature of $95^{\circ}$ C after development of the SU-8.

The propagation loss of the integrated waveguide fabricated with a $5-10 \mu \mathrm{m}$ thick SU-8 adhesion layer spun onto a borosilicate lid shows an increase of about $3 \mathrm{db} / \mathrm{cm}$ in the whole wavelength range compared to the waveguide with the PDMS lid. The increase is attributed to radiation loss in the upper part of the waveguide, because the adhesion layer and the waveguide core had the same refractive index, so the light was unguided in this region. This can be overcome by using an adhesion layer of a lower refractive index.

\section{CHEMICAL ABSORBANCE CELLS}

Fig. 4. shows a microscope picture of a finished device, where light from an Argon-ion laser was coupled across a $1000 \mu \mathrm{m}$ long absorbance cell through the integrated waveguides. The picture corresponds to the lower part of the design in Fig. 1. The channel width in this case was $30 \mu \mathrm{m}$ and bonding was achieved by pressing a $500 \mu \mathrm{m}$ thick borofloat glass wafer with an intermediate layer of PDMS against the SU-8 structure of the bottom substrate. The light path of the absorbance cell was visualized by filling the channel network with a 170 $\mu \mathrm{M}$ fluorescein solution. Excitation of the fluorescein solution was achieved by coupling light with a wavelength of $488 \mathrm{~nm}$ from an Argon-ion laser that was connected to the integrated waveguide in the right side of the picture through an inserted optical fiber.



Figure 4. Microscope picture of a $1000 \mu \mathrm{m}$ long chemical absorbance cell with integrated optical waveguides. The channel was filled with a $170 \mu \mathrm{M}$ fluorescein solution to visualize the light path, when light from an Argon-ion laser $(488 \mathrm{~nm})$ was coupled into the excitation waveguide.

In another absorbance cell, the width $(100 \mu \mathrm{m})$ of a separation channel was used as the optical path length. The performances of the absorbance cells were investigated by measuring a calibration curve of each cell (Fig. 5) at $633 \mathrm{~nm}$ with the dye Bromothymol Blue (Sigma-Aldrich, Denmark).

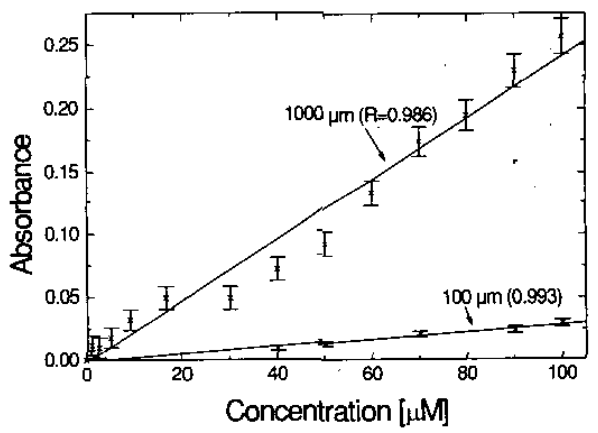

Figure 5. Calibration curves of absorbance cells with a nominal path length of $100 \mu \mathrm{m}$ and $1000 \mu \mathrm{m}$, respectively. The measurements ${ }^{2}$ were done with the dye Bromothymol Blue at $633 \mathrm{~nm}$.

Based on these measurements, the sensitivity, limit of detection and effective path length of the absorbance cells were determined (Table 1). The sensitivity was given by the slope of the calibration curve, while the limit of detection was determined for a signal-to-noise ratio of two. The effective optical path length was calculated by normalization with absorbance measurements on a commercial spectrometer (Ultrospec 3000, Pharmacia Biotech, U.S.A.). This procedure is described in detail in [12].

TRANSDUCERS '03 
Table 1. Sensitivity, limit of detection (LOD) and effective path length for absorbance cells with a nominal length of $100 \mu \mathrm{m}$ and $1000 \mu \mathrm{m}$.

\begin{tabular}{l|c|c} 
Nominal path length $[\mu \mathrm{m}]$ & $100 \mu \mathrm{m}$ & $1000 \mu \mathrm{m}$ \\
\hline Sensitivity $\times 10^{3}\left[\mathrm{M}^{-1}\right]$ & $0.3 \pm 0.02$ & $2.4 \pm 0.1$ \\
Limit of detection $[\mu \mathrm{M}]$ & $30 \pm 5$ & $15 \pm 5$ \\
Eff. path length $[\mu \mathrm{m}]$ & $113 \pm 8$ & $906 \pm 40$
\end{tabular}

The decrease in limit of detection was only about twofold when going from a $100 \mu \mathrm{m}$ to a $1000 \mu \mathrm{m}$ long absorbance cell, even though the increase in sensitivity was about eight-fold. The reason for this is due to an increase in the coupling loss from $5 \mathrm{~dB}(100 \mu \mathrm{m})$ to $20 \mathrm{~dB}$ $(1000 \mu \mathrm{m})$, which increases the relative error of the measured light intensity and hence lowers the $S / N$, as seen by eq. 2 . The lowest limit of detection was only $15 \mu \mathrm{M}$ (1000 $\mu \mathrm{m}$ path length). This is mainly due to roise in the light source, since an unstabilized HeNe laser was used.

\section{CONCLUSIONS}

The spectrally resolved propagation loss of integrated polymer waveguides with microfluidic channels was determined for three bonding procedures. The lowest loss was $1.4 \mathrm{~dB} / \mathrm{cm}$ at $633 \mathrm{~nm}$ and was achieved for PDMS bonding.

Two chemical absorbance cells with an optical path length of $100 \mu \mathrm{m}$ and $1000 \mu \mathrm{m}$ were furthermore fabricated and tested in terms of sensitivity, limit of detection and influence of stray light by absorbance measurement at $633 \mathrm{~nm}$ with the dye Bromothymol Blue. The decrease in limit of detection between the $100 \mu \mathrm{m}$ and the $1000 \mu \mathrm{m}$ long absorbance cell was only about two, even though the increase in sensitivity was about 8 . This discrepancy is attributed to an increased relative error of the measured light intensity in the case of the long absorbance cell, which in turn was due to an increase in the coupling loss over the channel.

\section{A'knowledgements}

The work was supported by the Danish Government's Scientific Research Council (STVF).

\section{References}

[1] J. El-Ali, K. B. Mogensen, I. R. P. Nielsen, J. P. Kutter, P. Telleman, and A. Wolff, "Integration of polymer waveguides for optical detection in biochemical microsystems", Proc. of uTAS 2002, Nara, Japan, p. 260 (2002).

[2] E. Verpoorte, A. Manz, H. Lüdi, A. E. Bruno, F. Maystre, B. Krattiger, H. M. Widmer, B. H. van der Schioot and N. F. de Rooij, "A silicon flow cell for optical detection in miniaturized total chemical analysis systems", Sens. Act. B, 6, 66-70 (1992).
[3] R. M. Tiggelaar, T. T. Veenstra, R. G. P. Sanders, J. G. E. Gardeniers, M. C. Elwenspoek and A. van den Berg, "A light detection cell to be used in a micro analysis system for ammonia", Talanta, 56, 331-339 (2002).

_[4] Z. Liang, N. Chiem, G. Ocvirk, T. Tang, K. Fluri, and D. J. Harrison, "Microfabrication of planar absorbance and fluorescence cell for integrated capillary electrophoresis devices", Anal. Chem, 68, 1040-1046 (1996).

[5] G. Pandraud, T. M. Koster, C. Gui, M. Dijkstra, A. van den Berg and P. V. Lambeck, "Evanescent wavesensing: new features for detection in small volumes", Sens. Act., A, 85, 158-162 (2000).

[6] N. J. Petersen, K. B. Mogensen and J. P. Kutter, "Performance of an in-plane detection cell with integrated waveguides for UV/Vis absorbance measurements on microfluidic devices", Electrophoresis, 23, 3528-3536 (2002).

[7] J. Zhang, K. L. Tan, G. D. Hong, L. J. Yang, and H. Q. Gong, "Polymerization optimization of SU-8 photoresist and its applications in microfluidic systems and MEMS", J. Micromech. Microeng. 11, 20-26 (2001).

[8] R. B. Jackman, T. M. Floyd, R. Ghodssi, M. A. Schmidt, and K. F. Jensen, "Microfluidic systems with on-line UV detection fabricated in photodefinable epoxy", J. Micromech. Microeng. 11, 263-269 (2001).

[9] L. Cui, T. Zhang and H. Morgan, "Optical particle detection integrated in a dielectrophoretic lab-on-a-chip", J. Micromech. Microeng. 12, 7-12 (2002).

[10] L. Eldada, K. M. T. Stengel, L. W. Shacklette, R. A. Norwood, C. Xu, C. Wu and J. Yardley, "Advanced polymer systems for optoelectronic integrated circuit applications", in Optoelectronic Integrated Circuits, Y. S. Park and R. V. Ramaswamy, eds., Proc. SPIE 3006, 344 61, (1997).

[11] J. N. McMullin, "Laser fabrication of integrated microfluidic/micro-optic systems", in Applications of Photonic Technology 4, R. A. Lessard and G. A. Lampropoulos, eds., Proc. SPIE 4087, 1050-1055 (2000).

[12] K. B. Mogensen, J. El-Ali, A. Wolff and J. P. Kutter, "Integration of polymer waveguides for optical detection in microfabricated chemical analysis systems". Applied Optics. Accepted for publication.

[13] G. B. Lee, C. H. Lin and G. L. Chang, "Multi-cellline micro flow cytometers with buried SU-8/SOG optical waveguides", Proc. MEMS 2002, Las Vegas, U.S.A, 503506 (2002).

TRANSDUCERS '03

The 12th International Conference on Solid State Sensors, Actuators and Microsystems, Boston, June 8-12, 2003 